Original

\title{
Butyric acid stimulates bone sialoprotein gene transcription
}

\author{
Li Yang ${ }^{1,2)}$, Zhengyang $\mathrm{Li}^{1,2)}$, Xinyue $\mathrm{Li}^{1,2)}$, Zhitao Wang ${ }^{1,2)}$, Shuang Wang ${ }^{1,3)}$, \\ Yoko Sasaki $^{1)}$, Hideki Takai ${ }^{1,4)}$ and Yorimasa Ogata ${ }^{1,4)}$ \\ ${ }^{1)}$ Department of Periodontology, Nihon University School of Dentistry at Matsudo, Chiba, Japan \\ 2) Tianjin Stomatology Hospital, Tianjin, China \\ ${ }^{3)}$ Stomatology College of Tianjin Medical University, Tianjin, China \\ ${ }^{4)}$ Research Institute of Oral Science, Nihon University School of Dentistry at Matsudo, Chiba, Japan
}

(Received 7 January and accepted 10 February 2010)

\begin{abstract}
Butyric acid (sodium butyrate; BA) is an extracellular metabolite secreted from periodontopathic bacteria present in subgingival plaque. BA induces apoptosis of $T$ and $B$ cells, and acts as a potent inhibitor of histone deacetylases. Bone sialoprotein (BSP) is thought to function in the initial mineralization of bone, and may be crucial for osteoblast differentiation, bone matrix mineralization and tumor metastasis. In the present study we investigated the regulation of BSP transcription by BA in rat osteoblast-like ROS17/2.8 cells. At $12 \mathrm{~h}, \mathrm{BA}\left(10^{-4} \mathrm{M}\right)$ increased the level of BSP mRNA, and enhanced the luciferase activity of the construct pLUC3, which includes the promoter sequence between nucleotides -116 and +60 . Transcriptional stimulation by $B A$ was abrogated in the pLUC3 construct which containing a 2-bp mutation in the fibroblast growth factor 2 response element (FRE). Gel shift analyses showed that BA increased the binding of nuclear protein to FRE. These data suggest that BA increases the transcription of the BSP gene mediated through FRE in the rat BSP gene promoter, and induces osteoblast activity in the early stage of bone formation. (J Oral Sci 52, 231-237, 2010)
\end{abstract}

Keywords: bone sialoprotein; butyric acid; bone formation; osteoblasts; transcription.

Correspondence to Dr. Yorimasa Ogata, Department of Periodontology, Nihon University School of Dentistry at Matsudo, 2-870-1 Sakaecho-nishi, Matsudo, Chiba 271-8587, Japan Tel: +81-47-360-9362

Fax: +81-47-360-9362

E-mail: ogata.yorimasa@nihon-u.ac.jp

\section{Introduction}

It has been recognized that periodontitis is an infectious condition, and that periodontal attachment loss results from interaction between specific anaerobic bacteria and host immune mechanisms (1). A recent study has indicated that multibacterial infection and certain combinations of periodontopathogens, including Porphyromonas gingivalis, Tannerella forsythesis, Prevotella intermedia and Fusobacterium nucleatum, are involved in the pathogenesis of periodontitis (2). Short-chain fatty acids (SCFA) (e.g., butyric acid, lactic acid and propionic acid) are bacterial metabolic by-products with significant biological activities, including the ability to alter cell proliferation, gene expression and apoptosis (3-5). Periodontal bacteria, in particular, release millimolar concentrations of SCFA into their environment (1), and these acids have been used to characterize the bacteria. Moreover, SCFA stimulates gingival inflammation via release of proinflammatory cytokines (6). Butyric acid (sodium butyrate; BA) is a major metabolic by-product of the main periodontopathic bacteria present in subgingival plaque $(2,7,8)$. Culture media used for growth of Porphyromonas gingivalis, Prevotella loescheii and Fusobacterium nucleatum can contain 13.3-26.8 mM butyric acid (1), and the concentration of butyric acid in subgingival plaque from patients with periodontitis can reach $14.4-20 \mathrm{mM}$; also its concentration in periodontal pockets has been shown to correlate with the severity of periodontal disease (9). Inflamed gingival fibroblasts from adult patients with periodontitis appear to be highly susceptible to mitochondria- and caspase-dependent apoptosis induced by BA, in comparison with healthy gingival fibroblasts (5). 
Moreover, BA is a potent inhibitor of histone deacetylases (HDACs) (10).

Bone sialoprotein (BSP) is a major non-collagenous protein found in mineralized connective tissues, and has been implicated in the nucleation of hydroxyapatite (1113). Studies on the developmental expression of BSP have shown that BSP mRNA is produced at high levels at the onset of bone, dentin and cementum formation (14). BSP is also expressed by breast, prostate and lung cancers and is associated with the formation of ectopic hydroxyapatite microcrystals in tumor tissues and tumor metastases $(13,15)$. The rat, mouse and human BSP genes have been cloned and partially characterized (16-20), and their promoters contain an inverted TATA box (-24 to -19) (21), an inverted CCAAT box $(-50$ to -46$)(22,23)$, a cAMP response element (CRE; -75 to -68) (24-26), a fibroblast growth factor 2 (FGF2) response element (FRE; -92 to $85)(24,27-30)$, a pituitary-specific transcription factor-1 (Pit-1) motif (-111 to -105) (31), and a homeodomain protein binding site (HOX; -199 to -192) $(30,32,33)$.

There have been a number of recent studies examining the effect of BA on the differentiation of many types of cells (34-37), and it has been suggested that BA promotes the differentiation and maturation of osteoblasts. Furthermore, BA stimulates mineralized nodule formation by increasing the gene and protein expression levels of type I collagen, osteopontin and BSP (38). In the present study, we analyzed the effects of BA on BSP gene transcription in rat osteoblast-like ROS17/2.8 cells.

\section{Materials}

\section{Materials and Methods}

Alpha minimum essential medium ( $\alpha$-MEM), fetal calf serum (FCS), Lipofectamine, penicillin, streptomycin, and trypsin were obtained from Invitrogen (Carlsbad, CA, USA). The pGL3-basic and pSV- $\beta$-galactosidase ( $\beta$-Gal) control vectors were purchased from Promega Co. (Madison, WI, USA). Butyric acid was purchased from Sigma-Aldrich (Steinheim, Germany). Rat osteoblast-like ROS17/2.8 cells were a gift from Dr. Jaro Sodek (39). All chemicals used were of analytical grade.

\section{Cell culture}

ROS17/2.8 cells were first grown to confluence in 60$\mathrm{mm}$ tissue culture dishes in $\alpha$-MEM containing $10 \%$ FCS, then cultured in $\alpha$-MEM without serum, followed by incubation with BA at doses ranging from $10^{-8}$ to $10^{-2} \mathrm{M}$ for $12 \mathrm{~h}$, or for $3-12 \mathrm{~h}$ at $10^{-4} \mathrm{M}$. Total RNA was isolated from triplicate cultures.

\section{Northern hybridization}

After BA treatment, total RNA was extracted from ROS17/2.8 cells using guanidinium thiocyanate. Aliquots $(20 \mu \mathrm{g})$ of total RNA were fractionated in $1.2 \%$ agarose gels and transferred to a Hybond-N+ membrane. Hybridizations were performed at $42^{\circ} \mathrm{C}$ with ${ }^{32} \mathrm{P}$-labeled rat BSP and glyceraldehyde-3-phosphate dehydrogenase (GAPDH) cDNA probes. The hybridized bands, representing the two polyadenylated forms (1.6 and 2.0 $\mathrm{kb}$ ) of rat BSP mRNA, were scanned using a Bio-imaging analyzer (Fuji BAS2500).

\section{Transient transfection assays}

Exponentially growing ROS17/2.8 cells were used for transfection assays. Twenty-four hours after plating, cells at $40-60 \%$ confluence were transfected using Lipofectamine reagent, $1 \mu \mathrm{g}$ of a luciferase (LUC) construct, and $2 \mu \mathrm{g}$ of $\beta$-Gal vector as an internal control. Two days after transfection, the cells were deprived of serum for $12 \mathrm{~h}$, and then BA $\left(10^{-4} \mathrm{M}\right)$ was added for $12 \mathrm{~h}$ prior to harvest. The luciferase assay was performed in accordance with the supplier's protocol using a luminescence reader (Acuu Flex Lumi 400; Aloka, Tokyo, Japan) for measurement of luciferase activities.

\section{Gel mobility shift assays}

Confluent ROS17.2.8 cells in T-75 flasks incubated for 3,6 and $12 \mathrm{~h}$ with $10^{-4} \mathrm{M}$ BA in $\alpha$-MEM without serum were used to prepare nuclear extracts. Nuclear protein was extracted according to the method of Dignam et al. (40) with the addition of extra proteinase inhibitors (extraction buffer contained $0.42 \mathrm{M} \mathrm{NaCl}, 1.5 \mathrm{mM} \mathrm{MgCl}_{2}$, $0.2 \mathrm{mM}$ EDTA, $1 \mathrm{mM}$ dithiothreitol (DTT), 25\% (v/v) glycerol, $0.5 \mathrm{mM}$ phenylmethyl-sulfonyl fluoride, $2 \mu \mathrm{g} / \mathrm{ml}$ leupeptin, $2 \mu \mathrm{g} / \mathrm{ml}$ pepstatin $\mathrm{A}, 1 \mu \mathrm{g} / \mathrm{ml}$ aprotinin, $\mathrm{pH}$ 7.9). Double-stranded oligonucleotides encompassing the inverted CCAAT (nts, -61 to $-37,5$ '-CCGTGACCGTG ATTGGCTGCTGAGA), CRE (nts, -84 to $-59,5$ 'CCCACAGCCTGACGTCGCACCGGCCG), FRE (nts, -98 to -79, 5'-TTTTCTGGTGAGAACCCACA), Pit-1 (nts, -115 to $-96,5$ '-CGTGTTGTAGTTACGGATTT) and HOX (nts, -204 to -179, 5'-TCCTCAGCCT TCAATTAAATCCCACA) motifs in the rat BSP promoter were prepared. For gel shift analysis, double-stranded oligonucleotides were end-labeled with $\left[\gamma^{32} \mathrm{P}\right] \mathrm{ATP}$ and T4 polynucleotide kinase. Nuclear protein extracts $(3 \mu \mathrm{g})$ were incubated for $20 \mathrm{~min}$ at room temperature with 0.1 pM radiolabeled double-stranded oligonucleotide, and then the protein-DNA complexes were resolved by electrophoresis on 5\% non-denaturing acrylamide gels (38:2 acrylamide/bis acrylamide) run at $200 \mathrm{~V}$ at RT. 
After electrophoresis, the gels were dried, and then autoradiograms were prepared and analyzed using an image analyzer.

\section{Statistical analysis}

Triplicate or quadruplicate samples were analyzed for each experiment, and the experiments were replicated to ensure the consistency of the responses to BA. Significance of differences between the control and BA treatments was determined using unpaired Student's $t$-test.

A

ROS $17 / 2.8$

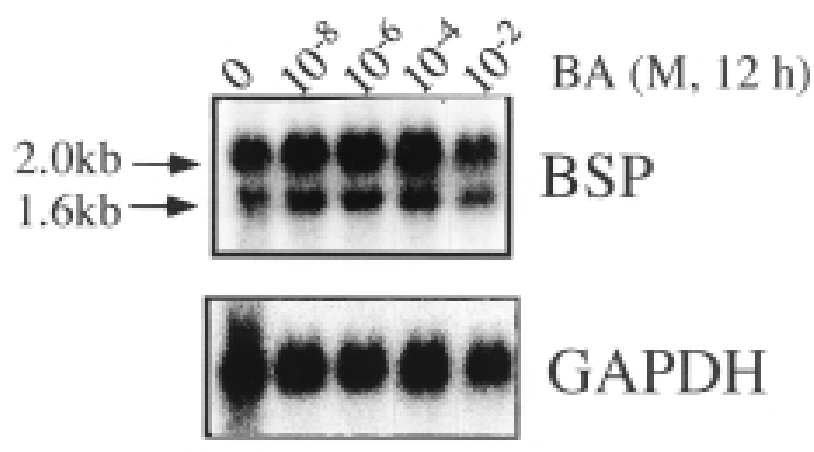

B

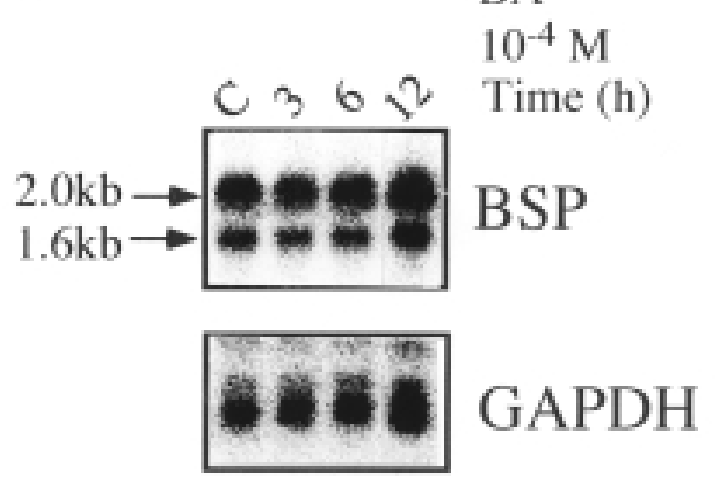

Fig. 1 Northern hybridization analysis of the effects of BA on expression of BSP mRNA. A: Dose-response effect of BA on BSP mRNA levels in osteoblast-like ROS17/2.8 cells treated for $12 \mathrm{~h}$. B: 12-h time course, revealing an increase of BSP mRNA following administration of $10^{-4} \mathrm{M}$ BA to ROS17/2.8 cells. Total RNA was isolated from triplicate cultures harvested after stimulation for 3, 6 and $12 \mathrm{~h}$ and used for Northern hybridization using BSP and GAPDH DNA probes. Results of representative hybridization analyses of control and BA-treated cells are shown.

\section{Results}

Stimulation of BSP mRNA expression in ROS 17/2.8 cells

To study the regulation of BSP expression by BA, we performed Northern hybridization analysis of total RNA extracted from osteoblastic ROS17/2.8 cells. First, the dose-response relationship for induction of BSP by BA was established by treating ROS17/2.8 cells with different concentrations of BA for $12 \mathrm{~h}$. BA increased the level of BSP mRNA at $10^{-8}, 10^{-6}$ and $10^{-4} \mathrm{M}$, and the maximal effect was observed at $10^{-4} \mathrm{M}$, whereas $10^{-2} \mathrm{M} \mathrm{BA}$ down-regulated the expression of BSP mRNA (Fig. 1A). This optimal level of BA was used to determine the time course of BSP mRNA expression. BA up-regulated the BSP mRNA level at $12 \mathrm{~h}$, but no effect on GAPDH was observed (Fig. 1B).

\section{Transient transfection analysis of rat BSP promoter constructs}

To further determine the effects of BA on the activation of BSP transcription, various-sized rat BSP promoters ligated to a luciferase reporter gene (pLUC1 - pLUC6, pLUC1; -18 to +60 , pLUC $2 ;-43$ to +60 , pLUC $3 ;-116$ to +60 , pLUC4; -425 to +60 , pLUC5; -801 to +60 and pLUC6; -938 to +60 ) were transiently transfected into ROS17/2.8 cells. The results of luciferase assays indicated

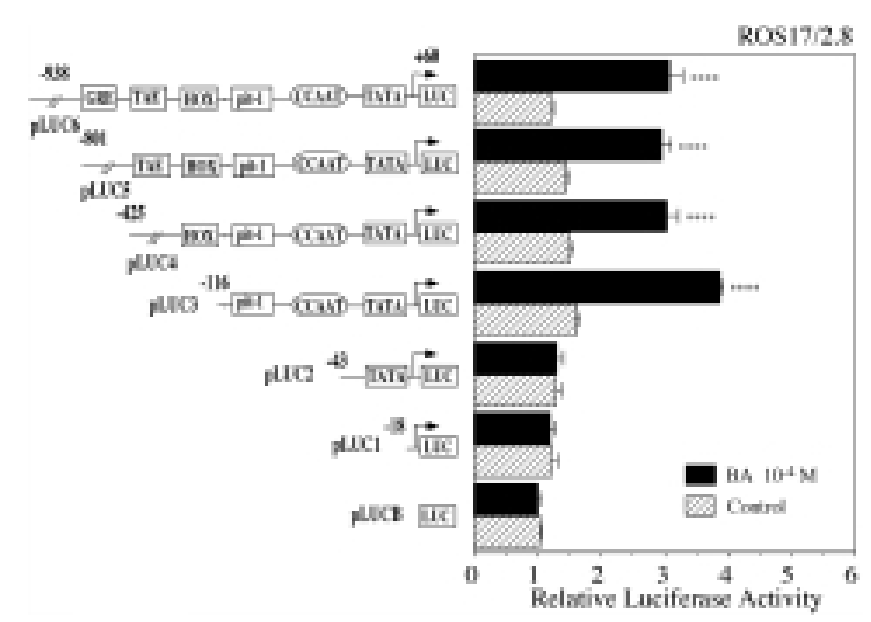

Fig. 2 BA up-regulates BSP promoter activity in ROS17/2.8 cells. Transient transfection of ROS17/2.8 cells in the presence or absence of BA $\left(10^{-4} \mathrm{M}\right)$ for $12 \mathrm{~h}$ was performed to determine the transcriptional activities of chimeric constructs that included various regions of the BSP promoter ligated to a luciferase reporter gene. The results of transcriptional activity obtained from four separate transfections with constructs pLUC basic (pLUCB), and pLUC1 to pLUC6 have been combined, and the values expressed with standard errors. Significant differences from control: $* * * *(P<0.01)$. 
increases in transcription after $12 \mathrm{~h}$ of treatment with $10^{-4} \mathrm{MBA}$ using the pLUC3, pLUC4, pLUC5 and pLUC6 constructs (Fig. 2). With shorter constructs (pLUC1 and pLUC2), luciferase activities were not increased by BA. The DNA sequence of the pLUC3 construct contains a unique inverted CCAAT box (ATTGG; nts -50 and -46), and CRE (nts -75 and -68), Runx2 (nts -84 and -79), FRE (nts -92 and -85) and Pit-1 (nts -111 and -105) motifs (Fig. 3 ). To determine more precisely the target sites in the BSP promoter through which the BA effect was mediated, we introduced 2-bp mutations in the putative response elements targeted by BA in pLUC3 (M-CCAAT, M-CRE and M-FRE) (Fig. 4). After introduction of these mutations, the basal activities of M-CCAAT, M-CRE and M-FRE were lower than the basal transcriptional activity of pLUC3. Transcriptional induction by BA was abrogated in MFRE (Fig. 4).

\section{Gel mobility shift assay}

To identify nuclear proteins that bind to CCAAT, CRE, FRE, Pit1 and HOX, double-stranded oligonucleotides were end-labeled and incubated with equal amounts $(3 \mu \mathrm{g})$

A

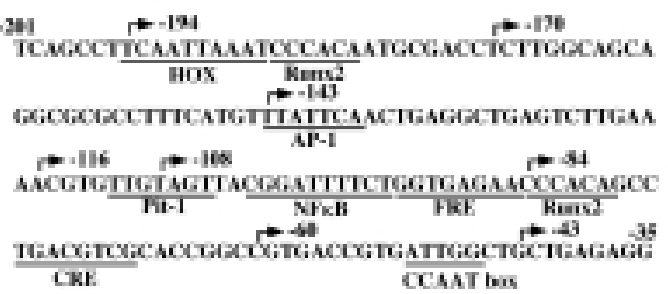

B

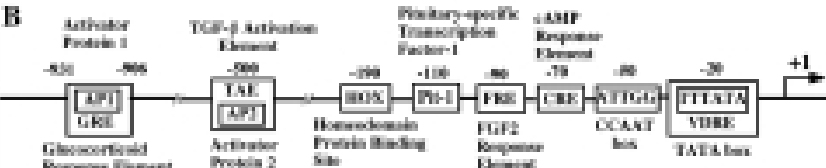

Fig. 3 Regulatory elements in the proximal rat BSP promoter. A: The nucleotide sequence of the rat BSP gene proximal promoter is shown from -201 to -35 . An inverted CCAAT box, and the CRE, Runx2, FRE, NFkB, Pit-1, AP1, Runx 2 and HOX motifs are present. $\mathrm{B}$ : The position of the inverted TATA box and CCAAT box overlapping with the Vitamin D3 response element (VDRE), cAMP response element (CRE), FGF2 response element (FRE), pituitary-specific transcription factor-1 (Pit-1), and homeodomain protein binding site (HOX), the TGF- $\beta$ activation element (TAE) overlapping with activator protein 2 (AP2), and the glucocorticoid response element (GRE) overlapping with activator protein 1 (AP1) are shown. Nucleotides are numbered relative to the transcription start site $(+1)$. of nuclear proteins extracted from confluent ROS17/2.8 cells that were either not treated (control) or treated with BA $\left(10^{-4} \mathrm{M}\right)$ for 3,6 and $12 \mathrm{~h}$. When we used the inverted CCAAT and HOX as probes, the DNA-protein complexes did not change after BA treatment (Fig. 5, lanes 1-4, 1720). With nuclear extracts from confluent control cultures of ROS17/2.8 cells, shift of the FRE-protein complex was evident (Fig. 5, lane 9). After stimulation by BA (3-12 h), FRE-protein complex formation was increased at 3,6 and $12 \mathrm{~h}$ (Fig. 5, lanes 10-12). BA did not induce formation of CRE- or Pit-1-protein complexes (Fig. 5, lanes 5-8, 13$16)$.

\section{Discussion}

BA induced the expression of BSP mRNA at $12 \mathrm{~h}$ in ROS17/2.8 cells (Fig. 1). The concentration of BA in subgingival plaque from periodontal pockets reportedly reaches 14.4 to $20 \mathrm{mM}(1,9)$. While BA at $10 \mathrm{mM}$ downregulated the expression of BSP mRNA, at $0.1 \mathrm{mM}\left(10^{-4}\right.$ $\mathrm{M})$ the expression of BSA mRNA was increased (Fig. 1A). Our results suggested that a low concentration of BA was able to induce bone formation. Transient transfection assays demonstrated that the luciferase activity of pLUC3

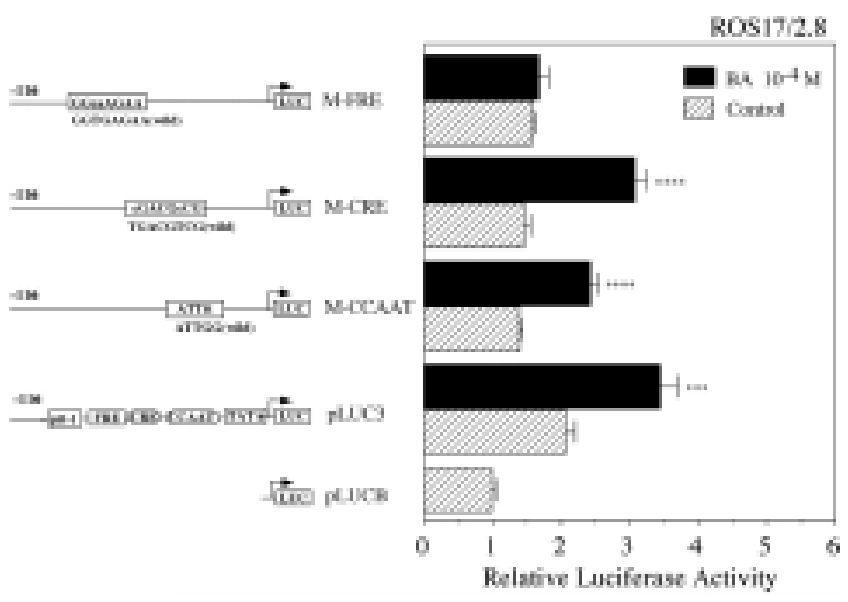

Fig. 4 Site mutation analysis of luciferase activities. Dinucleotide substitutions were made within the context of the homologous -116 to +60 (pLUC3) BSP promoter fragments. M-CCAAT (ATTtt), M-CRE (cGACGcCG) and M-FRE (GGcaAGAA) constructs were analyzed for relative promoter activity after transfection into ROS17/2.8 cells, and examined for induction after treatment with BA $\left(10^{-4} \mathrm{M}\right)$ for $12 \mathrm{~h}$. The results of transcriptional activity obtained from four separate transfections with the constructs were combined, and the values are expressed with standard errors. Significant differences from control: *** $(P<0.02)$; **** $(P<$ $0.01)$. 


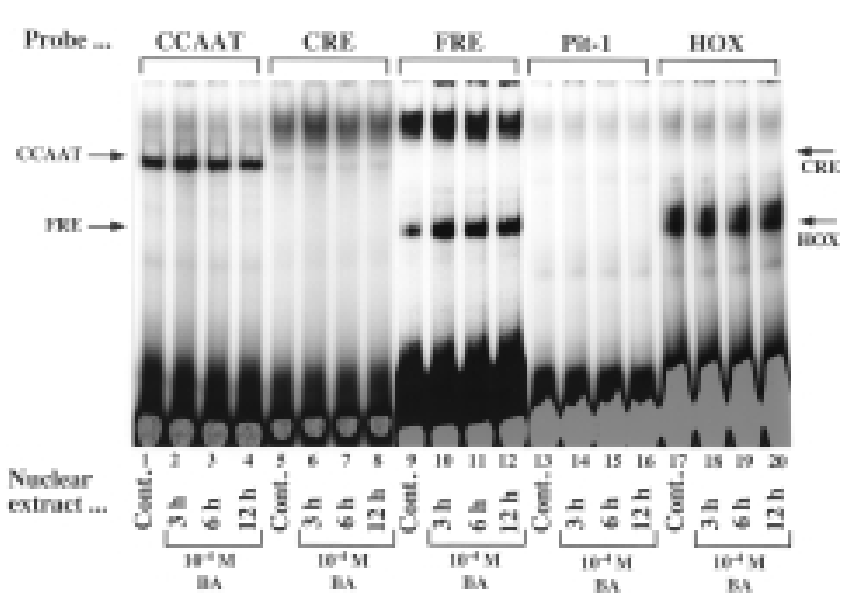

Fig. 5 Gel mobility shift analysis of inverted CCAAT, CRE, FRE, Pit-1 and HOX oligonucleotides. Radiolabeled double-stranded CCAAT (lanes 1-4), CRE (lanes 58), FRE (lanes 9-12), Pit-1 (lanes 13-16) and HOX (lanes 17-20) were incubated with nuclear protein extracts $(3 \mu \mathrm{g})$ obtained from ROS $17 / 2.8$ cells stimulated without (lanes 1, 5, 9, 13 and 17) or with BA $\left(10^{-4} \mathrm{M}\right)$ for $3 \mathrm{~h}$ (lanes 2, 6, 10, 14 and 18), $6 \mathrm{~h}$ (lanes 3, 7, 11, 15 and 19) and $12 \mathrm{~h}$ (lanes 4, 8, 12, 16 and 20). DNA-protein complexes were separated on $5 \%$ polyacrylamide gel in low-ionic-strength Trisborate buffer, dried under vacuum, and exposed to an imaging plate for quantitation by image analysis.

was increased by BA $\left(10^{-4} \mathrm{M}, 12 \mathrm{~h}\right)$, suggesting that factors binding to the promoter region of pLUC3 are crucial for BA-induced BSP transcription. The results of the mutation luciferase assay suggested that FRE is required for optimal induction of BSP transcription by BA (Fig. 4). The involvement of FRE in the regulation of BSP transcription by BA was confirmed in the gel mobility shift assays; the formation of FRE-protein complex was increased at 3, 6 and $12 \mathrm{~h}$ upon treatment with BA (Fig. 5).

Transcription activators often associate with histone acetyltransferases (HATs) to increase target gene expression, whereas transcription repressors frequently interact with histone deacetylases (HDACs) to downregulate target gene expression (41). As coregulators, HDACs have been recently implicated in tissue differentiation. There are several reports that HDACs act as regulators of bone metabolism. BA inhibits the enzymatic activity of HDACs by competing with the HDAC substrate at the enzyme active site pocket containing its catalytic center (5). BA is able to enhance osteogenesis and the expression of osteoblast marker genes in several types of osteogenic cells, suggesting that modulation of endogenous HDAC enzymatic activity is important for execution of the osteogenic program (38).

In summary, we have shown that the FRE element in the rat BSP gene promoter mediates the stimulatory effects of BA on BSP gene transcription. Since BSP is expressed specifically in mineralized connective tissues, and BA is a major metabolic product of periodontopathic bacteria, BA may up- or down-regulate bone formation and periodontal tissue regeneration. It is conceivable that BA could be used for periodontal therapy in the future.

\section{Acknowledgments}

This work was funded in part by a Grant for the Support of Projects for Strategic Research in Private Universities by the Ministry of Education, Culture, Sports, Science, and Technology (MEXT), 2008-2012, and by a Nihon University Multidisciplinary Research Grant for 20092010.

\section{References}

1. Kurita-Ochiai T, Fukushima K, Ochiai K (1995) Volatile fatty acids, metabolic by-products of periodontopathic bacteria, inhibit lymphocyte proliferation and cytokine production. J Dent Res74, 1367-1373.

2. Dahlén G (1993) Role of suspected periodontopathogens in microbiological monitoring of periodontitis. Adv Dent Res 7, 163-174.

3. Tse CS, Williams DM (1992) Inhibition of human endothelial cell proliferation in vitro in response to n-butyrate and propionate. J Periodont Res 27, 506510.

4. Vinolo MA, Hatanaka E, Lambertucci RH, Newsholme P, Curi R (2009) Effects of short chain fatty acids on effector mechanisms of neutrophils. Cell Biochem Funct 27, 48-55.

5. Kurita-Ochiai T, Seto S, Suzuki N, Yamamoto M, Otsuka K, Abe K, Ochiai K (2008) Butyric acid induces apoptosis in inflamed fibroblasts. J Dent Res 87, 51-55.

6. Niederman R, Zhang J, Kashket S (1997) Short-chain carboxylicacid-stimulated PMN-mediated gingival inflammation. Crit Rev Oral Biol Med 8, 269-290.

7. Botta GA, Radin L, Costa A, Schito G, Blasi G (1985) Gas-liquid chromatography of the gingival fluid as an aid in periodontal diagnosis. J Periodontal Res 20, 450-457.

8. Umemoto T, Nakazawa F, Hoshino E, Okada K, Fukunaga M, Namikawa I (1997) Treponema medium sp. nov., isolated from human subgingival dental plaque. Int J Syst Bacteriol 47, 67-72.

9. Kurita-Ochiai T, Fukushima K, Ochiai K (1997) 
Butyric acid-induced apoptosis of murine thymocytes, splenic $\mathrm{T}$ cells, and human Jurkat $\mathrm{T}$ cells. Infect Immun 65, 35-41.

10. Imai K, Ochiai K, Okamoto T (2009) Reactivation of latent HIV-1 infection by the periodontopathic bacterium Porphyromonas gingivalis involves histone modification. J Immunol 182, 3688-3695.

11. Hunter GK, Goldberg HA (1993) Nucleation of hydroxyapatite by bone sialoprotein. Proc Natl Acad Sci U S A 90, 8562-8565.

12. Ganss B, Kim RH, Sodek J (1999) Bone sialoprotein. Crit Rev Oral Biol Med 10, 79-98.

13. Ogata Y (2008) Bone sialoprotein and its transcriptional regulatory mechanism. J Periodontal Res 43, 127-135.

14. Chen J, Shapiro HS, Sodek J (1992) Development expression of bone sialoprotein mRNA in rat mineralized connective tissues. J Bone Miner Res 7, 987-997.

15. Waltregny D, Bellahcène A, de Leval X, Florkin B, Weidle U, Castronovo V (2000) Increased expression of bone sialoprotein in bone metastases compared with visceral metastases in human breast and prostate cancers. J Bone Miner Res 15, 834-843.

16. Li JJ, Sodek J (1993) Cloning and characterization of the rat bone sialoprotein gene promoter. Biochem J 289, 625-629.

17. Benson MD, Aubin JE, Xiao G, Thomas PE, Franceschi RT (1999) Cloning of a $2.5 \mathrm{~kb}$ murine bone sialoprotein promoter fragment and functional analysis of putative Osf2 binding sites. J Bone Miner Res 14, 396-405.

18. Kerr JM, Fisher LW, Termine JD, Wang MG, McBride OW, Young MF (1993) The human bone sialoprotein gene (IBSP): genomic localization and characterization. Genomics 17, 408-415.

19. Kim RH, Shapiro HS, Li JJ, Wrana JL, Sodek J (1994) Characterization of the human bone sialoprotein (BSP) gene and its promoter sequence. Matrix Biol 14, 31-40.

20. Kiyoshima T, Yamauchi M, Wong C, Jheon A, Ganss B, Sodek J (2002) An L1 element disrupts human bone sialoprotein promoter: lack of tissuespecific regulation by distalless5 (Dlx5) and runt homeodomain protein 2 (Runx2)/core binding factor a1 (Cbfa1) elements. Gene 299, 205-217.

21. Li JJ, Kim RH, Sodek J (1995) An inverted TATA box directs downstream transcription of the bone sialoprotein gene. Biochem J 310, 33-40.

22. Kim RH, Sodek J (1999) Transcription of the bone sialoprotein gene is stimulated by $\mathrm{v}$-Src acting through an inverted CCAAT box. Cancer Res 59, 565-571.

23. Shimizu E, Ogata Y (2002) Activation of bone sialoprotein gene transcription by flavonoids is mediated through an inverted CCAAT box in ROS 17/2.8 cells. J Cell Biochem 86, 35-44.

24. Samoto H, Shimizu E, Matsuda-Honjyo Y, Saito R, Nakao S, Yamazaki M, Furuyama S, Sugiya H, Sodek J, Ogata Y (2003) Prostaglandin E2 stimulates bone sialoprotein (BSP) expression through cAMP and fibroblast growth factor 2 response elements in the proximal promoter of the rat BSP gene. J Biol Chem 278, 28659-28667.

25. Araki S, Mezawa M, Sasaki Y, Yang L, Li Z, Takai H, Nakayama Y, Ogata Y (2009) Parathyroid hormone regulation of the human bone sialoprotein gene transcription is mediated through two cAMP response elements. J Cell Biochem 106, 618-625.

26. Mezawa M, Araki S, Takai H, Sasaki Y, Wang S, Li X, Kim D, Nakayama Y, Ogata Y (2009) Regulation of human bone sialoprotein gene transcription by platelet-derived growth factor-BB. Gene 435, 80-87.

27. Shimizu-Sasaki E, Yamazaki M, Furuyama S, Sugiya H, Sodek J, Ogata Y (2001) Identification of a novel response element in the rat bone sialoprotein (BSP) gene promoter that mediates constitutive and fibroblast growth factor 2-induced expression of BSP. J Biol Chem 276, 5459-5466.

28. Shimizu E, Saito R, Nakayama Y, Nakajima Y, Kato N, Takai H, Kim D, Arai M, Simmer J, Ogata Y (2005) Amelogenin stimulates bone sialoprotein (BSP) expression through fibroblast growth factor 2 response element and TGF- $\beta 1$ activation element in the promoter of the BSP gene. J Periodontol 76, 1482-1489.

29. Shimizu E, Nakayama Y, Nakajima Y, Kato N, Takai H, Kim DS, Arai M, Saito R, Sodek J, Ogata Y (2006) Fibroblast growth factor 2 and cyclic AMP synergistically regulate bone sialoprotein gene expression. Bone 39, 42-52.

30. Nakayama Y, Nakajima Y, Kato N, Takai H, Kim DS, Arai M, Mezawa M, Araki S, Sodek J, Ogata Y (2006) Insulin-like growth factor-I increases bone sialoprotein (BSP) expression through fibroblast growth factor-2 response element and homeodomain protein-binding site in the proximal promoter of the BSP gene. J Cell Physiol 208, 326-335.

31. Ogata Y, Nakao S, Kim RH, Li JJ, Furuyama S, Sugiya H, Sodek J (2000) Parathyroid hormone regulation of bone sialoprotein (BSP) gene 
transcription is mediated through a pituitary specific transcription factor-1 (Pit-1) motif in the rat BSP gene promoter. Matrix Biol 19, 395-407.

32. Benson MD, Bargeon JL, Xiao G, Thomas PE, Kim A, Cui Y, Franceschi RT (2000) Identification of a homeodomain binding element in the bone sialoprotein gene promoter that is required for its osteoblast-selective expression. J Biol Chem 275, 13907-13917.

33. Shimizu E, Nakajima Y, Kato N, Nakayama Y, Saito R, Samoto H, Ogata Y (2004) Regulation of rat bone sialoprotein gene transcription by enamel matrix derivative. J Periodontol 75, 260-267.

34. Wang YW, Wu Q, Chen GQ (2004) Attachment, proliferation and differentiation of osteoblasts on random biopolyester poly (3-hydroxybutyrate-co3-hydroxyhexanoate) scaffolds. Biomaterials 25, 669-675.

35. Chen TH, Chen WM, Hsu KH, Kuo CD, Hung SC (2007) Sodium butyrate activates ERK to regulate differentiation of mesenchymal stem cells. Biochem Biophys Res Commun 355, 913-918.

36. Lee HW, Suh JH, Kim AY, Lee YS, Park SY, Kim JB (2006) Histone deacetylase 1-mediated histone modification regulates osteoblast differentiation.
Mol Endocrinol 20, 2432-2443.

37. Zhao Y, Zou B, Shi Z, Wu Q, Chen GQ (2007) The effect of 3-hydroxybutyrate on the in vitro differentiation of murine osteoblast MC3T3-E1 and in vivo bone formation in ovariectomized rats. Biomaterials 28, 3063-3073.

38. Katono T, Kawato T, Tanabe N, Suzuki N, Iida T, Morozumi A, Ochiai K, Maeno M (2008) Sodium butyrate stimulates mineralized nodule formation and osteoprotegerin expression by human osteoblasts. Arch Oral Biol 53, 903-909.

39. Ogata Y, Yamauchi M, Kim RH, Li JJ, Freedman LP, Sodek J (1995) Glucocorticoid regulation of bone sialoprotein (BSP) gene expression. Identification of a glucocorticoid response element in the bone sialoprotein gene promoter. Eur J Biochem 230, 183-192.

40. Dignam JD, Lebovitz RM, Roeder RG (1983) Accurate transcription initiation by RNA polymerase II in a soluble extract from isolated mammalian nuclei. Nucleic Acids Res 11, 1475-1489.

41. Ng HH, Bird A (2000) Histone deacetylases: silencers for hire. Trends Biochem Sci 25, 121126. 